OPEN $\odot$ ACCESS Freely available online

http://www.banglajol.info/index.php/BJID/index

Original Article

Bangladesh Journal of Infectious Diseases

December 2015, Volume 2, Number 2

ISSN (online) 2411-670X

ISSN (Print) 2411-4820

\title{
Socio-demographic Characteristics of Campylobacter jejuni infected Diarrhoeal Patients under 5 Years
}

\author{
Nasreen Huda $^{1}$, Sofia Andalib ${ }^{2}$, Md. Abdullah Yusuf ${ }^{3}$
}

${ }^{1}$ Assistant Professor, Department of Microbiology, Shahabuddin Medical College, Dhaka, Bangladesh; ${ }^{2}$ Professor \& Head, Department of Microbiology, Medical College for Women and Hospital, Dhaka, Bangladesh; ${ }^{3}$ Assistant Professor \& Head, Department of Microbiology, National Institute of Neurosciences \& Hospital, Dhaka, Bangladesh

[Received: 1 February 2015; Accepted: 15 March 2015; Published: 1 June 2015]

\begin{abstract}
Background: Campylobacter jejuni infected diarrhoea can occur in different socioeconomic condition among the children under 5 years. Objective: The purpose of the present study was to see the socioeconomic condition among the Campylobacter jejuni infected diarrhoea children under 5 years of age. Methodology: This was a cross sectional study conducted in the Department of Microbiology at Banghabanhdhu Sheikh Mujib Medical University (BSMMU), Dhaka from July 2007 to June 2008 for a period of 1(one) year. All the diarrhoeal samples were collected from outdoor unit of ICDDR,B. Children up-to 5 years of age with acute diarrhoea with or without blood and mucous associated with either fever or abdominal pain or both were included as study population. Stool samples were collected from all diarrhoeal children in a sterile collection pot. Detection of Campylobacter antigen was performed from stool samples. The inoculated selective media in the candle jar were incubated at $42^{\circ} \mathrm{C}$ (microaerophilic condition) for 48 hours which is favorable for the growth of the organism. With the above criteria it is confirmed as Campylobacter, further identification of suspected Campylobacter jejuni and Campylobacter coli was confirmed by standard test. Result: Two hundred and seventeen children up-to 5 years of age who were suffering from acute diarrhoea were studied to assess the rate of infection by Campylobacter jejuni and Campylobacter coli as an enteric pathogen. Among 217 diarrhoeal children, Campylobacter were isolated from 28(12.9\%) cases. Isolation rate of Campylobacter was 19.3\% in below 1 year of age group and 5.8\% was above 1 year of age group ( $\mathrm{p}<0.003)$. Out of 217 study patients 141 were male and 76 were female and the isolation rate of Campylobacter were 20(14.2\%) from male and $8(10.5 \%)$ from female respectively ( $p>0.05$ ). About $50.0 \%$ Campylobacter positive patients were belong to lower class and $35.7 \%$ were in middle class. Conclusion: In conclusion Campylobacter jejuni infected diarrhoea children under 5 years of age are mostly below 1 year of age with a predominance of male. [Bangladesh Journal of Infectious Disease 2015;2(2):33-36]

Keywords: Socioeconomic condition; Campylobacter jejuni; children under 5 years; diarrhoea

[How to Cite this article: Huda N, Andalib S, Yusuf MA. Socio-demographic Characteristics of Campylobacter jejuni infected Diarrhoeal Patients under 5 Years. Bangladesh Journal of Infectious Disease 2015;2(2):33-36]

Corresponding Author: Dr. Nasreen Huda, Assistant Professor, Department of Microbiology, Shahabuddin Medical College and Hospital, Gulshan-2, Dhaka, Bangladesh; Email: nasreen.eva@gmail.com; Cell no.: +8801711000007

Conflict of Interest: Authors have declared no conflict of interest.

Contributions to authors: NH \& SA have contributed from protocol preparation to manuscript writing as well as in data collection. MAY has prepared and has revised the manuscript.
\end{abstract}




\section{Introduction}

Acute diarrhoea is one of the leading causes of morbidity and mortality in children in most developing areas of the world ${ }^{1}$. In the last ten years, the number of viral, bacterial, and parasitic agents identified in person with diarrhoeal disease in developing countries has doubled ${ }^{2}$. Despite the use of oral rehydration therapy, deaths due to diarrhoea in children aged less than five years are still estimated to be about two million per year ${ }^{3}$. ICDDR,B in Bangladesh treats more than 100000 patients in a year, and this number is increasing year after year. ${ }^{4}$ The purpose of the present study was to see the socioeconomic condition among the Campylobacter jejuni infected diarrhoea children under 5 years of age.

\section{Methodology}

This was a cross-sectional study conducted in the Department of Microbiology at Banghabanhdhu Sheikh Mujib Medical University (BSMMU), Dhaka from July 2007 to June 2008 for a period of 1(one) year. All the diarrhoeal samples were collected from outdoor unit of ICDDR,B, Dhaka. In this research institute patient came from various places. The laboratory work was done both in Laboratory science division (LSD) of ICCDDR,B and the laboratory of Microbiology \& Immunology Department at BSMMU, Dhaka. Children up-to 5 years of age with acute diarrhoea with or with out blood and mucous associated with either fever or abdominal pain or both were included as study population. Diarrhoeal children having antibiotic for last two weeks due to other reason were excluded from this study. Socioeconomic conditions were ascertained by the income of the head of the family. Stool samples were collected from all diarrhoeal children in a sterile collection pot. Immediately after collection, specimens were directly inoculated into primary selective medium for Campylobacter species in the laboratory of ICDDR,B. Then the inoculated media were kept in a candle jar and transported to laboratory of BSMMU within 2 to 4 hours. The rest of the stool samples were transported from collection site to laboratory of BSMMU for inoculation on MacConkey's and Salmonella-Shigella agar media for isolation of Salmonella and Shigella. This inoculation was completed as soon as possible not later than 4 to $6 \mathrm{hrs}$ of collection. After finishing the inoculation, rest of the stool samples were then preserved in refrigerator at $-20^{\circ} \mathrm{C}$ in Microbiology and immunology department of BSMMU until tested for antigen detection. Biochemical tests were also done to identify the species. Detection of Campylobacter antigen was performed from stool samples. Routine stool examination was also done from all stool samples. The primary culturing medium for Campylobacter used was Brucella agar base with defibrinated 5\% sheep blood containing Polymixin B $2.5 \mathrm{IU} / \mathrm{ml}$, Trimethoprim $5 \mathrm{mg} / \mathrm{liter}$, Cephalothin $15 \mathrm{mg} /$ liter, Vancomycin $10 \mathrm{mg} / \mathrm{liter}$, and Amphoterecin B 2mg/liter. The inoculated selective media in the candle jar were incubated at $42^{0} \mathrm{C}$ (microaerophilic condition) for 48 hours which is favorable for the growth of the organism. The suspected colony was identified as Campylobacter jejuni and Campylobacter coli according to established criteria ${ }^{5}$. Statistical analysis was performed by using SPSS version 11.5.

\section{Results}

Two hundred and seventeen children up-to 5 years of age who were suffering from acute diarrhoea were studied to assess the rate of infection by Campylobacter jejuni and Campylobacter coli as an enteric pathogen. Among 217 diarrhoeal children, Campylobacter were isolated from 28(12.9\%) cases. Highest number of Campylobacter positive cases were from 0 to 1 year of age group which was $22(19.3 \%)$ cases followed by in 1-2 years of age $(7.1 \%)$ and in 2-3 years of age group $(6.9 \%)$. Campylobacter isolation rate among the 3 to 4 and 4 to 5 years age group children were $1(4.3 \%)$ cases and $1(4.3 \%)$ cases respectively (Table 1 ).

Table 1: Isolation rate of Campylobacter from stool sample among different age group of diarrhoeal children $(n=217)$

\begin{tabular}{llcc}
\hline \multirow{2}{*}{$\begin{array}{l}\text { Age } \\
\text { group }\end{array}$} & \multicolumn{2}{c}{ Campylobacter Isolates } & Total \\
\cline { 2 - 3 } & \multicolumn{1}{c}{ Positive } & Negative & \\
\hline 0 to 1 Yrs & $22(19.3 \%)$ & $92(80.7 \%)$ & $114(100.0 \%)$ \\
1 to 2 Yrs & $2(7.1 \%)$ & $26(92.9 \%)$ & $28(100.0 \%)$ \\
2 to 3 Yrs & $2(6.9 \%)$ & $27(93.1 \%)$ & $29(100.0 \%)$ \\
3 to 4 Yrs & $1(4.3 \%)$ & $22(95.7 \%)$ & $23(100.0 \%)$ \\
4 to 5 Yrs & $1(4.3 \%)$ & $22(95.7 \%)$ & $23(100.0 \%)$ \\
Total & $\mathbf{2 8 ( 1 2 . 9 \% )}$ & $\mathbf{1 8 9}(\mathbf{8 7 . 1 \%})$ & $\mathbf{2 1 7 ( 1 0 0 . 0 \% )}$ \\
\hline
\end{tabular}

Isolation rate of Campylobacter was $19.3 \%$ in below 1 year of age group and 5.8\% was above 1 year of age group. The difference was highly significant $(p<0.003)($ Table 2).

\section{Table 2: Socioeconomic Status of Campylobacter Positive Cases ( $\mathbf{n = 2 8}$ )}

\begin{tabular}{lcc}
\hline SE Condition & Frequency & Percentage \\
\hline Upper Class & 4 & 14.3 \\
Middle Class & 10 & 35.7
\end{tabular}




\begin{tabular}{lcc} 
Lower Class & 14 & 50.0 \\
Total & $\mathbf{2 8}$ & $\mathbf{1 0 0 . 0}$ \\
\hline
\end{tabular}

Out of 217 study patients 141 were male and 76 were female and the isolation rate of Campylobacter were $20(14.2 \%)$ from male and $8(10.5 \%)$ from female respectively. The difference was not significant ( $\mathrm{p}>0.05$ ) in $\mathrm{Z}$ test where $\mathrm{Z}=0.807$ (Table 3).

Table 3: Isolation rate of Campylobacter in age group upto 1 year and above in diarrhoeal children

\begin{tabular}{lccc}
\hline $\begin{array}{l}\text { Age } \\
\text { group }\end{array}$ & \multicolumn{2}{c}{ Culture Growth } & Total \\
\cline { 2 - 3 } & Positive & Negative & \\
\hline <1 year & $22(19.3 \%)$ & $92(80.7 \%)$ & $114(100.0 \%)$ \\
$>$ 1 year & $6(5.8 \%)$ & $97(94.2 \%)$ & $103(100.0 \%)$ \\
Total & $\mathbf{2 8 ( 1 2 . 9 \% )}$ & $\mathbf{1 8 9 ( 8 7 . 1 \% )}$ & $\mathbf{2 1 7 ( 1 0 0 . 0 \% )}$ \\
\hline
\end{tabular}

*p value $=0.0003$

About $50.0 \%$ Campylobacter positive patients were belong to lower class and $35.7 \%$ were in middle class. Only $14.3 \%$ Campylobacter positive children were belong to upper class (Table 4).

Table 4: Results of Campylobacter positive Cases among Diarrhoeal Children in Respect of Sex

\begin{tabular}{lccl}
\hline Gender & \multicolumn{2}{c}{ Culture Growth } & \multicolumn{1}{c}{ Total } \\
\cline { 2 - 3 } & Positive & Negative & \\
\hline Male & $20(14.2 \%)$ & $121(85.8 \%)$ & $141(100.0 \%)$ \\
Female & $8(10.5 \%)$ & $68(89.5 \%)$ & $76(100.0 \%)$ \\
Total & $\mathbf{2 8 ( 1 2 . 9 \% )}$ & $\mathbf{1 8 9}(\mathbf{8 7 . 1 \%})$ & $\mathbf{2 1 7}(\mathbf{1 0 0 . 0 \%})$ \\
\hline
\end{tabular}

$*$ p value $=0.05$

\section{Discussion}

Acute diarrhoea is still the important health problem of children in developing countries ${ }^{6}$. One of the major pathogen of diarrhoea is Campylobacter and is the most frequent cause of bacterial diarrhoea in developed as well as in developing countries. Campylobacter is an invasive microorganism that has been associated with both diarrhoeal and systemic disease ${ }^{7}$. During the last 2 decades, major advances methods have been made to isolate Campylobacter species.

In this study, the diarrhoeal children upto 5 years of age were included for this study because it is seen that Campylobacter affects all age group but has fimodal age distribution with peak in children younger than 4 years ${ }^{8}$. Jain et $\mathrm{al}^{9}$ reported that, Campylobacter infection significantly higher among children aged less than 5 years of age which was $10.96 \%$ up to 5 years of age and $5.97 \%$ above 5 years of age. It has been postulated that the higher incidence rates seen in this group of children may be due to over sampling of this age group, because parents may be more likely to seek medical care for their children ${ }^{10}$. Among bacterial causes of diarrhoea, the five most common bacterial pathogens in children up to five years of age is Campylobacter jejuni (17.4\%) followed by Escherichia coli (ETEC) (16.8\%), Aeromonas spp. (12.2\%), Shigella (9.2\%) and Vibrio cholerae $(9 \%)^{4}$. In Thailand, children up to five years of age, the five most common bacterial causes of diarrhoea are Campylobacter (13.3\%) followed by Shigella species (12.6\%), Salmonella species (12.3\%) and Escherichia coli (ETEC) $(9.1 \%)$, Plesiomonas $(2.5 \%)^{5}$. On the other hand, in developed country like United States, Salmonella is found the most common bacterial agent (7.5\%) followed by Shigella (3.9\%), Campylobacter jejuni (3.8\%), and Escherichia coli $0157(0.8 \%)^{6}$.

It was found in the present study, that the isolation rate of Campylobacter in diarrhoeal children was significantly higher up to 1 year age which was $19.3 \%$ and $5.8 \%$ was above 1 year of age group children. The difference was significant $(\mathrm{p}<0.003)$. Similar observation was seen by Haq and Rahman ${ }^{11}$ that isolation rate of Campylobacter was 32.8\% upto 1 year age group children and $15.9 \%$ above 1 year age group children. Here the difference was also significant $(\mathrm{p}<0.001)$. In Thailand Campylobacter were associated with $18.8 \%$ of cases among diarrhoeal children younger than 12 months, $12.3 \%$ were in aged 12 to 23 months, and $10.3 \%$ of cases among those aged 24 to 59 months ${ }^{12}$. The high incidence below 1 year age group can be due to, infants start walking and seating in this age and they try to put many thing in their mouth and thus can get infected. Weaning period also start within this age so there is always a high chance of this child to have diarrhoea and also infants are less immune. It is also clearly seen that isolation rate was gradually decreasing with increasing of age. The cause of decrease rate of infection by Campylobacter with increasing age may be due to acquisition of immunity because it is claimed that in developing countries repeated infection in young children induces immunity ${ }^{13}$. Patients infected with Campylobacter developed specific immunoglobin $\operatorname{IgG}$, IgM and IgA antibody in their serum and $\operatorname{IgA}$ antibody is intestinal secretions ${ }^{13}$. In developing country, specific serum IgA levels rise progressively with age, reflecting recurring exposer to Campylobacter.

It is noticed in the present study that, among 217 diarrhoeal children 20(14.2\%) were male and $8(10.5 \%)$ were female. No significant difference 
$(\mathrm{p}>0.05)$ in Campylobacter isolation rate between male and female population was observed. Previous study in Bangladesh, also demonstrated that among the isolation rate of Campylobacter, $27.9 \%$ were male and $21.9 \%$ were female and the difference was not significant $(\mathrm{p}>0.05)^{11}$. Moore et $\mathrm{al}^{14}$ also reported similar finding where male female ratio was 1:0.7. It is observed that more male children are attending in the hospital for treatment. It reflects that, male children may get more attention and care in the society than the female children.

\section{Conclusion}

In conclusion Campylobacter jejuni infected diarrhoea children under 5 years of age are mostly below 1 year of age. Furthermore majority of the patients were male. However, most of the patients are from low socio-economic condition. There is a significant relationship with the culture positivity and the age of the patients. Again the isolation rate of Campylobacter jejuni is significantly associated with difference of the gender of the patients. Large scale multicentre study should be carried out to see the scenario of Bangladesh.

\section{References}

1. Bemis K, Marcus R, Hadler JL. Socioeconomic status and campylobacteriosis, Connecticut, USA, 1999-2009. Emerging infectious diseases. 2014 Jul;20(7):1240-41

2. Centers for Disease Control and Prevention. Incidence and trends of infection with pathogens transmitted commonly through food-Foodborne Diseases Active Surveillance Network. MMWR Morb Mortal Wkly Rep. 2013;62:283-7

3. Rosenberg Goldstein RE, Cruz-Cano R, Jiang C, Palmer A, Blythe D, Ryan P, Hogan B, White B, Dunn JR, Libby T, Tobin-D'Angelo M. Association between community socioeconomic factors, animal feeding operations, and campylobacteriosis incidence rates: Food-borne Diseases Active Surveillance Network (FoodNet), 2004-2010. BMC Infectious Diseases. 2016;16:354
4. Albert MJ, Faruque AS, Faruque SM, Sack RB, Mahalanabis D. Case-control study of enteropathogens associated with childhood diarrhea in Dhaka, Bangladesh. Journal of clinical microbiology. 1999;37(11):3458-64

5. Coker AO, Isokpehi RD, Thomas BN, Amisu KO, Obi CL. Human campylobacteriosis in developing countries synopsis-statistical data included. Emerg Infect Dis. 2002; 8(3):237-43

6. Samuel MC, Vugia DJ, Shallow S, Marcus R, Segler S, McGivern T, Kassenborg H, Reilly K, Kennedy M, Angulo F, Tauxe RV. Epidemiology of sporadic Campylobacter infection in the United States and declining trend in incidence, FoodNet 1996-1999. Clinical Infectious Diseases 2004;38(Supplement 3):S165-74

7. Olson CK, Ethelberg S, van Pelt W, Tauxe RV. Epidemiology of Campylobacter jejuni infections in industrialized nations. InCampylobacter, Third Edition 2008 Jan 1 (pp. 163-189). American Society of Microbiology

8. Albert MJ, Leach A, Asche V, Hennessy J, Penner JL. Serotype distribution of Campylobacter jejuni and Campylobacter coli isolated from hospitalized patients with diarrhea in central Australia. Journal of Clinical Microbiology 1992;30(1):207-10

9. Jain D, Sinha S, Prasad KN, Pandey CM. Campylobacter species and drug resistance in a north Indian rural community. Transactions of the Royal Society of Tropical Medicine and Hygiene 2005;99(3):207-14

10. Lastovica AJ. Emerging Campylobacter spp.: the tip of the iceberg. Clinical Microbiology Newsletter 2006;28(7):4956

11. Haq JA, Rahman KM. Campylobacter jejuni as a cause of acute diarrhoea in children: a study at an urban hospital in Bangladesh. The Journal of Tropical Medicine and Hygiene 1991;94(1):50-4

12. Acheson D, Allos BM. Campylobacter jejuni infections: update on emerging issues and trends. Clinical Infectious Diseases 2001;32(8):1201-6

13. Lastovica AJ, Allos BM. Clinical significance of Campylobacter and related species other than Campylobacter jejuni and Campylobacter coli. In Campylobacter, Third Edition 2008;123-149; American Society of Microbiology.

14. Moore JE, Barton MD, Blair IS, Corcoran D, Dooley JS, Fanning S, Kempf I, Lastovica AJ, Lowery CJ, Matsuda M, McDowell DA. The epidemiology of antibiotic resistance in Campylobacter. Microbes and Infection 2006;8(7):195566 